\title{
APLICACIÓN DE HERRAMIENTAS CARTOGRÁFICAS Y CENSALES EN UN ESTUDIO HISTORIOGRÁFICO DEL DISTRITO CENTRAL DE BARVA, 1945-2014
}

\section{APPLICATION OF CARTOGRAPHIC AND CENSUAL TOOLS IN A HISTORIOGRAPHICAL STUDY OF THE CENTRAL DISTRICT OF BARVA, 1945-2014}

\author{
Marcela Otárola Guevara ${ }^{1}$ \\ Consultora independiente, Costa Rica
}

http://dx.doi.org/10.15359/rgac.3-59.11

\section{RESUMEN}

El estudio de las ciudades, desde una perspectiva historiográfica, se beneficia del utillaje de otras disciplinas para comprender la magnitud de los cambios que en ellas ocurren. Por tal motivo, una investigación en Historia Urbana hecha en el Distrito Central de Barva, ciudad de Costa Rica, se apoyó en el uso de fotografías aéreas, mapas y registros de población para comprender su transformación de un lugar rural a uno urbano entre los años 1945 y 2014. Se presentará el uso dado a herramientas cartográficas y censales en el ámbito de una investigación de Historia Aplicada. Con ellas se definieron tres periodos, cada uno con una configuración diferenciada, y se expuso la variación demográfica de sus habitantes, observando así la modificación de la morfología urbana como una acción directa del ser humano.

1 Magister Scientiae en Historia Aplicada, arquitecta, profesional independiente, investigadora en Historia Urbana, Costa Rica, motarolag@gmail.com. 
Marcela Otárola Guevara. Application of cartographic and censual tools in a historiographical study of the Central District of Barva, 1945-2014

Palabras clave: morfología urbana, historia aplicada, cartografía aplicada, censos demográficos, Barva

\begin{abstract}
The study of cities, from a historiographical perspective, it benefits from the tools of other disciplines to understand the magnitude of the changes that occur in them. Therefore, a research in Urban History made in the Central District of Barva, city of Costa Rica, relied on the use of aerial photos, maps and population registers to understand its transformation from a rural setting to an urban one, between 1945 and 2014.

The use of mapping and census research tools will be showed in an Applied History research. As a result of its use, three periods were defined, each one with a different configuration, and a demographic transformation was exposed, thus observing the modification of the urban morphology as a direct action of the human being.
\end{abstract}

Keywords; urban morphology, applied history, applied cartography, population censuses, Barva

\title{
Introducción
}

Las relaciones humanas se expresan en las urbes y es por ello que tienen una dimensión geográfica. Sus interacciones están espacializadas, resultan de distintas coyunturas y, por esta razón, son variables y provocan cambios en el comportamiento de los individuos, quienes, a su vez, modifican su forma de vincularse con el contexto. Así, las ciudades son concebidas como asentamientos inacabados, porque están en constante mutación y, con una visión historiográfica, se puede apreciar la metamorfosis de su estructura urbana.

Bajo una perspectiva teórica permeada por el constructivismo social, en la que se considera la ciudad como la impronta de una realidad social en elaboración, se realizó una investigación sobre la transformación del Distrito Central de Barva, como trabajo final de graduación en el programa de la Maestría en Historia Aplicada de la Universidad Nacional, con el fin de comprender cómo sus habitantes modificaron el espacio urbano mediante distintas formas de apropiación. Así, se procedió a compilar y analizar información proveniente de distintas fuentes como textos, entrevistas, observaciones de campo e imágenes sobre costumbres locales; además tuvo un caracter medular la información obtenida de la observación de mapas y fotografías aéreas y de la interpretación de datos inscritos en registros de población. Con los recursos cartográficos y censales, principalmente, se visibilizaron las permutas originadas por migraciones internas en la Gran 
Área Metropolitana (GAM) acontecidas desde la segunda mitad del siglo XX hasta los albores del siglo XXI, mismas que provocaron una transformación del uso del suelo: se pasó de un territorio rural a uno urbano.

El sistema económico decimonónico que definió a Barva como un área agropecuaria cambió con la metropolización (Carvajal, 2005), este cambio le confirió otra especificidad a la localidad: la otrora agraria en la década de 1940 que contaba con un núcleo compuesto por el templo católico, la plaza y el edificio municipal, donde se intercalaban casas con cultivos (en su mayoría cafetales), en un plazo de setenta años se convirtió en un sector habitacional conurbado con el Distrito Central de la provincia de Heredia, modificando su composición territorial y demográfica.

En el presente artículo, se muestra el uso de mapas como herramienta para dilucidar esta variación, haciendo pesquisas comparativas entre ellos. Como resultado de este ejercicio se establecieron tres períodos, delimitados según los cambios significativos observados en la composición urbana. Uno abarca desde 1940 hasta 1969, otro considera los comprendidos entre 1970 y 1989; mientras que el último contempla aquellos de 1990 al 2014. El primero retrata a Barva como una comunidad agrícola con un centro delimitado y una población homogénea; el segundo muestra el efecto de las migraciones en el aumento de los habitantes, la densificación de su Distrito Central y el crecimiento de asentamientos perimetrales; y, finalmente, en el tercero se evidencia la diversificación de la población barveña y la unión de la jurisdicción con localidades vecinas.

Como complemento a la datos cartográficos, se utilizaron mapas censales, registros agropecuarios y de población, normativas de ordenamiento urbano, documentos sobre el proceso de urbanización local e imágenes históricas de la ciudad. Por último, se encontraron hallazgos que facilitaron la comprensión de la morfología de la zona en estudio, permitiendo formular una explicación (razonamiento) sobre la configuración de la estructura social del centro urbano barveño.

\section{El objeto de estudio}

La investigación se enfocó en examinar el impacto que produjo en el espacio urbano de una comunidad, el cambio cuantitativo y cualitativo de su población, como consecuencia de los fenómenos de migración interna acaecidos dentro de la Gran Área Metropolitana (GAM). El sitio se encuentra en 
el Distrito Central de Barva, cantón número 2 de la provincia de Heredia, ubicado al norte del Valle Central de Costa Rica. Colinda con San Pablo, San Roque y Santa Lucía de Barva al norte, al oeste y al este respectivamente, $\mathrm{y}$ al sur con el distrito de Mercedes que pertenece al cantón central de Heredia. Temporalmente, se estudió lo ocurrido entre los años 1945 y el 2014, período que inicia con la época previa a la metropolización y finaliza con el proceso de desaceleración del aumento poblacional.

\section{Metodología}

Esta investigación fue un estudio retrospectivo que usó como fuentes de información primaria los siguientes recursos:

- $\quad$ Fotografías aéreas del Instituto Geográfico Nacional (IGN) de 1945, 1960, 1980, 1985, 1992, 1997 y 2014.

- Mapas censales de la Dirección General de Estadística y Censos de 1962, 1972 y 1982.

- Censos de población de la Dirección General de Estadística y Censos de 1950, 1963 y 1973.

- $\quad$ Censos de población del Instituto Nacional de Estadística y Censos (INEC) del 2000 y 2011.

- Censos agropecuarios de la Dirección General de Estadística y Censos de 1973 y 1984.

- $\quad$ Estimaciones de población de 1970, 1980, 1990, 2000, 2010 y 2015, elaboradas por el que Luis Rosero Bixby del Centro Centroamericano de Población de la Universidad de Costa Rica (CCP).

En los trabajos de Solera (1964) y Rodríguez (1997) se encontraron mapas del distrito central, estadísticas demográficas y narraciones sobre el crecimiento del centro urbano; mientras que en el Diagnóstico de Planificación del Plan Regulador de Barva de Heredia (DEPPAT, 2006), en el Plan Regulador de Barva de Heredia (DEPPAT, 2008) y en el Plan de Desarrollo Humano Local de Barva 2015-2020 (Municipalidad de Barva, 2014), se obtuvo información sobre el desarrollo de servicios e infraestructura urbana incluidos en programas vinculados al ordenamiento territorial del sitio.

Como complemento, datos sobre la repercusión de nuevos proyectos habitacionales en la infraestructura y en los servicios urbanos de la zona

Revista Geográfica de América Central No 59 ISSN 1011-484X, julio-diciembre 2017, pp. 341-366 
indagada fueron provistos por informantes locales, quienes fueron entrevistados durante la investigación.

Tras hacer una revisión documental, se estableció una línea de tiempo, usando como fechas de referencia los años de las fotografías aéreas suministradas por el Instituto Geográfico Nacional (IGN). Al comparar estas imágenes, se observaron los cambios en el espacio urbano y, para cuantificarlo en términos de superficie, se procedió a georeferenciarlas, usando el programa de cómputo ArcGis y como parte de la investigación se representó en mapas con la indicación de dos formas de uso del suelo: rural y urbano. Con base en estos mapas, se hizo un cuadro comparativo, en el cual se anotaron las fechas y las áreas correspondientes al espacio urbano (medidas en hectáreas y metros cuadrados), cuyo cotejo permitió establecer su crecimiento porcentual.

Posteriormente, se examinó la información de los censos y de las normas de ordenamiento urbano del lugar. Se realizaron periodizaciones, considerando el año de registro de los datos contenidos en las fuentes, se sistematizaron los apuntes demográficos para establecer un perfil de la población tomando en cuenta las cuantificaciones de habitantes en distritos y cantones, su procedencia, ocupación y residencia; mientras que del conjunto normativo se extrajo el uso del suelo y la configuración territorial del distrito central.

Con esa información, se construyeron cuadros comparativos que revelaron el comportamiento demográfico como parte del proceso se midió el incremento de la población, su distribución en los asentamientos, la proporción de migrantes y las actividades productivas de los habitantes. La huella de los pobladores en el área de estudio se obtuvo haciendo zonificaciones en los planos de la localidad.

Finalmente, se consolidó la información cartográfica en un solo mapa, con lo que se observó la mutación de lo rural a urbano, mientras que con los datos censales se estableció el cambio en la población.

\section{Resultados}

Período 1940-1969

Mapas de 1945 y 1960 muestran en Barva una vocación agropecuaria heredada del siglo XIX. Se observó un núcleo poblacional que, si bien se señala urbano por la concentración de población, la prestación de 
Marcela Otárola Guevara. Application of cartographic and censual tools in a historiographical study of the Central District of Barva, 1945-2014

servicios, por la confluencia vial y comercial, así como por la disposición residencial en torno a la Iglesia y la plaza; mantenía amplios espacios de cultivo, la mayoría de los cuales se cultivaban para autoconsumo. El trazo de las calles demarcó la trama de la ciudad, más que la construcción propiamente edilicia, y fue uno de los elementos ordenadores del territorio, ya que orientó el crecimiento del Distrito Central y sus alrededores (Mapa 1). 


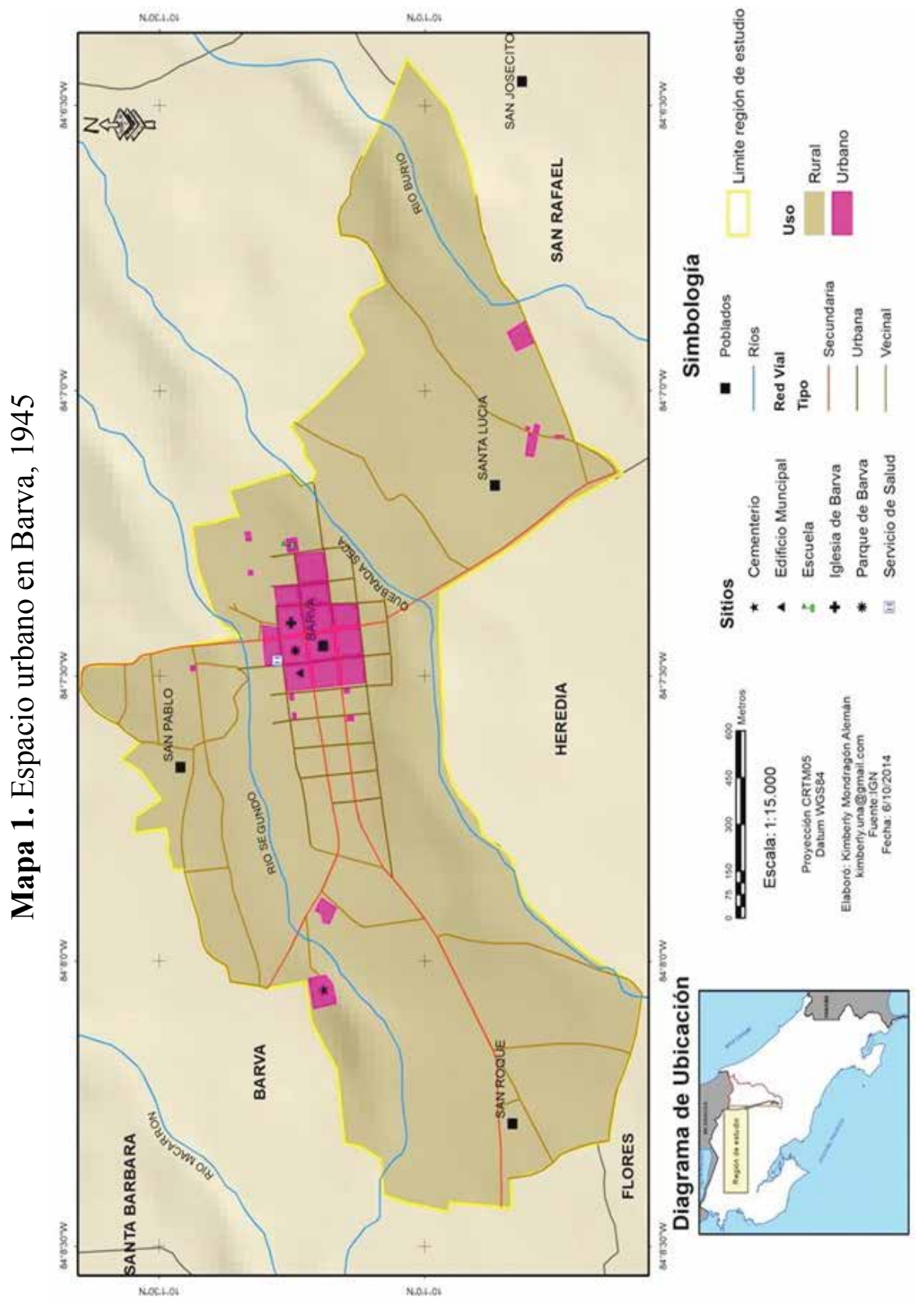

合 
Observando las inscripciones de población del Instituto Nacional de Estadística y Censos (INEC) de los años 1950 y 1963, se aprecia que la población originaria se mantuvo en ascenso, mientras que la cifra de inmigrantes bajó un $9 \%$ en este periodo; lo que indica que no hubo movimientos migratorios significativos y que el incremento se debe al aumento de la tasa vegetativa. Es importante destacar que el $50.9 \%$ de los trabajadores activos del cantón se dedicaban a labores agropecuarias en 1963, mostrando que la agricultura aún se mantenía como una actividad económica relevante en la localidad (Tabla 1).

Tabla 1. Hallazgos censales y cartográficos del cantón de Barva, referentes al uso de suelo y población, 1940-1969

\begin{tabular}{|c|c|c|}
\hline Año & Fuente & Hallazgos \\
\hline 1945 & Mapa de 1945 & $\begin{array}{l}\text { Zona rural con vocación agrícola. } \\
\text { Destaca el trazo vial como uno de los elementos ordenadores } \\
\text { del espacio. } \\
\text { Incipiente asentamiento urbano en torno a la iglesia, la plaza } \\
\text { y el edificio municipal. }\end{array}$ \\
\hline 1950 & $\begin{array}{l}\text { Censo de } \\
\text { población }\end{array}$ & 5.263 personas viven en el cantón, $68,73 \%$ son oriundas. \\
\hline 1960 & Mapa de 1960 & $\begin{array}{l}\text { Desarrollo concéntrico del asentamiento alrededor de la } \\
\text { iglesia, la plaza y el edificio municipal. } \\
\text { Carreteras como factor de crecimiento urbano del distrito central. } \\
\text { Incorporación de un nuevo punto de referencia y de crecimiento } \\
\text { urbano: la escuela Pedro Murillo en el este del distrito. } \\
\text { Prevalencia de zona rural. }\end{array}$ \\
\hline 1963 & $\begin{array}{l}\text { Censo de } \\
\text { población }\end{array}$ & $\begin{array}{l}\text { 8.504 personas viven en el cantón: } 77,74 \% \text { son oriundas, } \\
\text { el } 26,87 \% \text { son activas laboralmente y, de éstas, el } 50,9 \% \text { se } \\
\text { dedican a actividades agropecuarias. }\end{array}$ \\
\hline
\end{tabular}

Fuente: (INEC, 1950, 1963; IGN, 1945, 1960).

Hasta 1960 el pueblo no presenta modificaciones en su forma urbana: conservó un centro compuesto por la iglesia, la plaza y el edificio municipal, el crecimiento se realizó en sentido oeste-este, siguiendo el sentido de los ríos Segundo y Quebrada Seca, que delimitan el distrito, y no se realizaron desplazamientos masivos de personas. Al norte y al sureste se vislumbran asentamientos embrionarios (San Pablo y Santa Lucía, respectivamente) junto a la ruta 126 , vía de acceso a Barva, que posteriormente se convertirán en densos núcleos habitacionales (Mapa 2). 


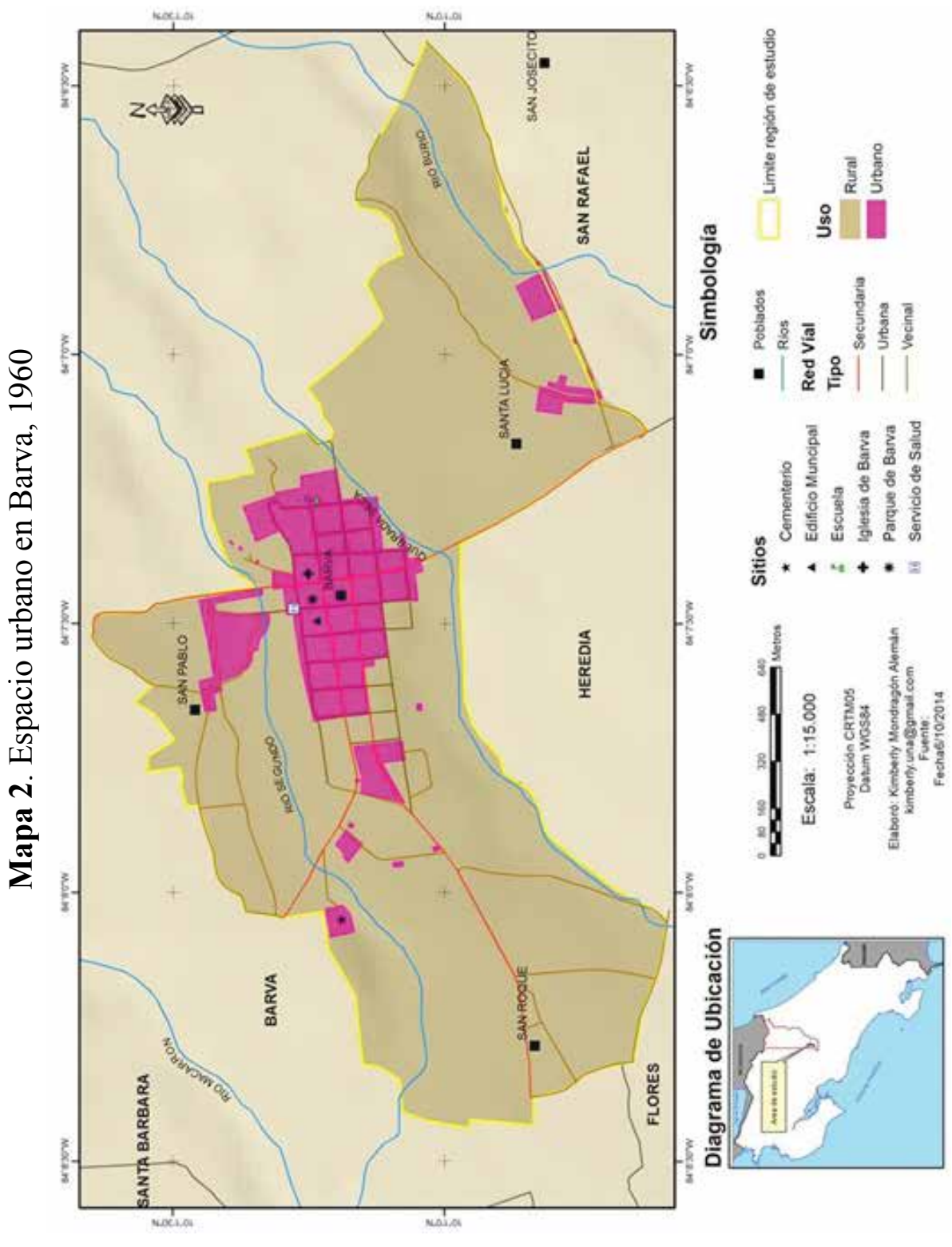

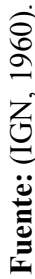


En la década siguiente la situación cambió, porque hubo un incremento de la población como consecuencia de "[...] la formación de un ámbito regional estructurado de las actividades económicas y sociales localizadas en la ciudad capital" (Carvajal, 2005, p. 53) que extendió su injerencia a cabeceras cantonales de las provincias vecinas, entre ellas, Barva.

\section{Período 1970-1989}

Al revisar las estimaciones de población de 1970 y 1980 (Rosero, 2002) se contabiliza el incremento de un $54.22 \%$ de la población barveña concentrada en el distrito central, y se advierte que un $25.38 \%$ de los residentes del cantón viven en esa jurisdicción, la que, para 1973, es considerada urbana, según datos del censo agropecuario del Instituto Nacional de Estadística y Censos (INEC) de ese año. Esta situación se refleja en la densificación de sus cuadras centrales, especialmente, en las inmediaciones de la iglesia y de la escuela Pedro Murillo (Tabla 2).

Tabla 2. Hallazgos censales y cartográficos del Cantón de Barva, referentes al uso de suelo y población, 1970-1980

\begin{tabular}{|c|l|l|}
\hline Año & \multicolumn{1}{|c|}{ Fuente } & \multicolumn{1}{c|}{ Hallazgos } \\
\hline 1970 & $\begin{array}{l}\text { Estimación } \\
\text { de población }\end{array}$ & $\begin{array}{l}11.425 \text { habitantes residen en el cantón de Barva. El mayor } \\
\text { porcentaje vive en el Distrito Central (25.38\%) y los de menor } \\
\text { proporción en Santa Lucía (12,3\%) y San Roque (6,1\%). }\end{array}$ \\
\hline 1973 & $\begin{array}{l}\text { Censo } \\
\text { agropecuario }\end{array}$ & $\begin{array}{l}24,3 \% \text { del área del cantón es zona urbana, correspondiendo } \\
\text { el 100\% al Distrito Central de Barva. }\end{array}$ \\
\hline \multirow{2}{*}{1980} & $\begin{array}{l}\text { Estimación } \\
\text { de población }\end{array}$ & $\begin{array}{l}17.620 \text { habitantes residen en el cantón de Barva. El 22\% en } \\
\text { el Distrito Central y con menor porcentaje en Santa Lucía } \\
(13,3 \%) \text { y San Roque (8,5\%). } \\
\text { Hay aumentos significativos de población en localidades } \\
\text { vecinas: San Roque (113\%), San Pedro (89,34\%) y San } \\
\text { Pablo (28,5\%). }\end{array}$ \\
\cline { 2 - 4 } & $\begin{array}{l}\text { Mapa de } \\
\text { 1980 }\end{array}$ & $\begin{array}{l}\text { Crecimiento urbano hacia el este, en dirección a la escuela } \\
\text { Pedro Murillo. } \\
\text { Aumento de la densidad edilicia en el centro de Barva. } \\
\text { Surgen incipientes asentamientos en San Roque y San Pablo. } \\
\text { Notable expansión urbana en Santa Lucía. }\end{array}$ \\
\hline \multirow{2}{*}{1984} & $\begin{array}{l}\text { Censo } \\
\text { agropecuario }\end{array}$ & $\begin{array}{l}\text { El distrito de Barva tiene la menor cantidad de hectáreas para } \\
\text { cultivo: 3,84\%, seguido de San Roque con un 5,87\% y Santa } \\
\text { Lucía con un 7,67\%. }\end{array}$ \\
\hline
\end{tabular}

Fuentes: (Rosero, 2002; INEC, 1973,1984; IGN, 1980). 
Por otra parte, si bien hay distritos que lucen despoblados a inicios de los años 70, su situación se revierte once años después. El caso más significativo es Santa Lucía que, entre 1970 y 1980, presenta un aumento del $67 \%$ de la población y una disminución del $41.6 \%$ en las tierras de uso agrícola entre 1973 y 1984. Al examinar su ubicación en fotografías aéreas de 1980 y 1985, se nota que la mayoría de sus construcciones son residenciales y se han levantado junto a la carretera nacional 126 que conduce a Barva; mientras que las fincas existentes han quedado relegadas al sector noreste que colinda con San Rafael de Heredia (Mapa 3).

Ambas situaciones iniciaron la conurbación de Barva con el cantón de Heredia y aumentó la circulación de flujos de personas y mercancías, desdibujándose, de este modo, la frontera física entre ambas localidades. Este tráfico se nutre del aumento de moradores en otros asentamientos como San Roque, San Pedro y San Pablo, todos interconectados por una red vial enlazada con otras localidades de la Gran Área Metropolitana (GAM), los cuales, en conjunto, constituyeron una huella urbana cantonal en expansión que desplazó las áreas agropecuarias hacia regiones de mayor altura. 
Marcela Otárola Guevara. Application of cartographic and censual tools in a historiographical study of the Central District of Barva, 1945-2014

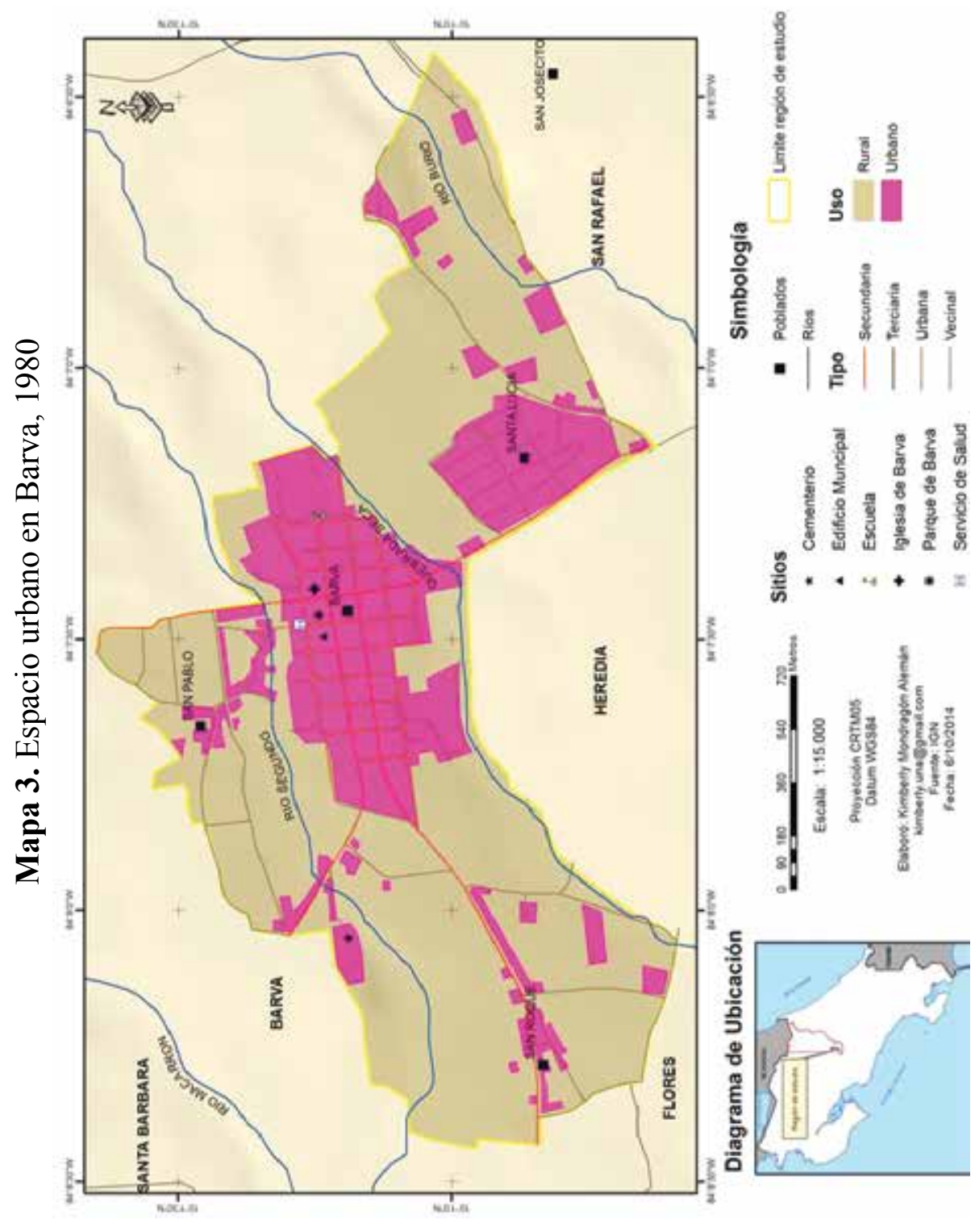

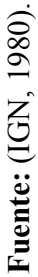




\section{Período 1990-2014}

Datos reportados por el investigador Luis Rosero Bixby (2002), indican que, a partir de 1990, inicia un descenso en la curva de crecimiento de la población; en ese año se reportó, en relación con 1980, un 40\% de incremento, empero, para el 2000 fue de un $35 \%$ y para el 2010 un $20 \%$. La desaceleración se observa también en los distritos, pero no altera la conversión de los espacios rurales en urbanos. Se tipifican como urbanos a los residentes en comunidades perimetrales al centro de Barva, según lo expresa el censo del Instituto Nacional de Estadística y Censos (INEC) del 2000, que indica: quienes viven en el distrito de Barva están en un sector $100 \%$ urbano, al igual que el 97,62\% de los habitantes de Santa Lucía y un 53,5\% de los vecinos de San Roque; mientras que un 59,7\% de los residentes de San Pablo viven en la periferia urbana.

Al concatenar estos datos con la información cartográfica del Instituto Geográfico Nacional (IGN) de 1992 y 2014, se colige que ellos conforman una ampliación del centro urbano de Barva (Mapa 4), situación favorecida por la cercanía de la red vial (Tabla 3). Así mismo, el comportamiento de los distritos perimetrales al central de Barva contribuye a esta propagación, debido a su transformación en sitios de atracción residencial que promueven el cambio del uso de suelo; estos espacios atienden una demanda habitacional que, además de brindar una vivienda, requieren servicios de infraestructura (calles, agua, telefonía, electricidad), cobertura social (clínicas y escuelas) y amenidades (parques, salones comunales, plazas y canchas deportivas); facilidades con las que estos lugares cuentan, según pesquisa realizada en el 2006 por los consultores de Desarrollos en Ecología, Paisajismo, Planificación, Arquitectura y Turismo (DEPPAT). 
Marcela Otárola Guevara. Application of cartographic and censual tools in a historiographical study of the Central District of Barva, 1945-2014

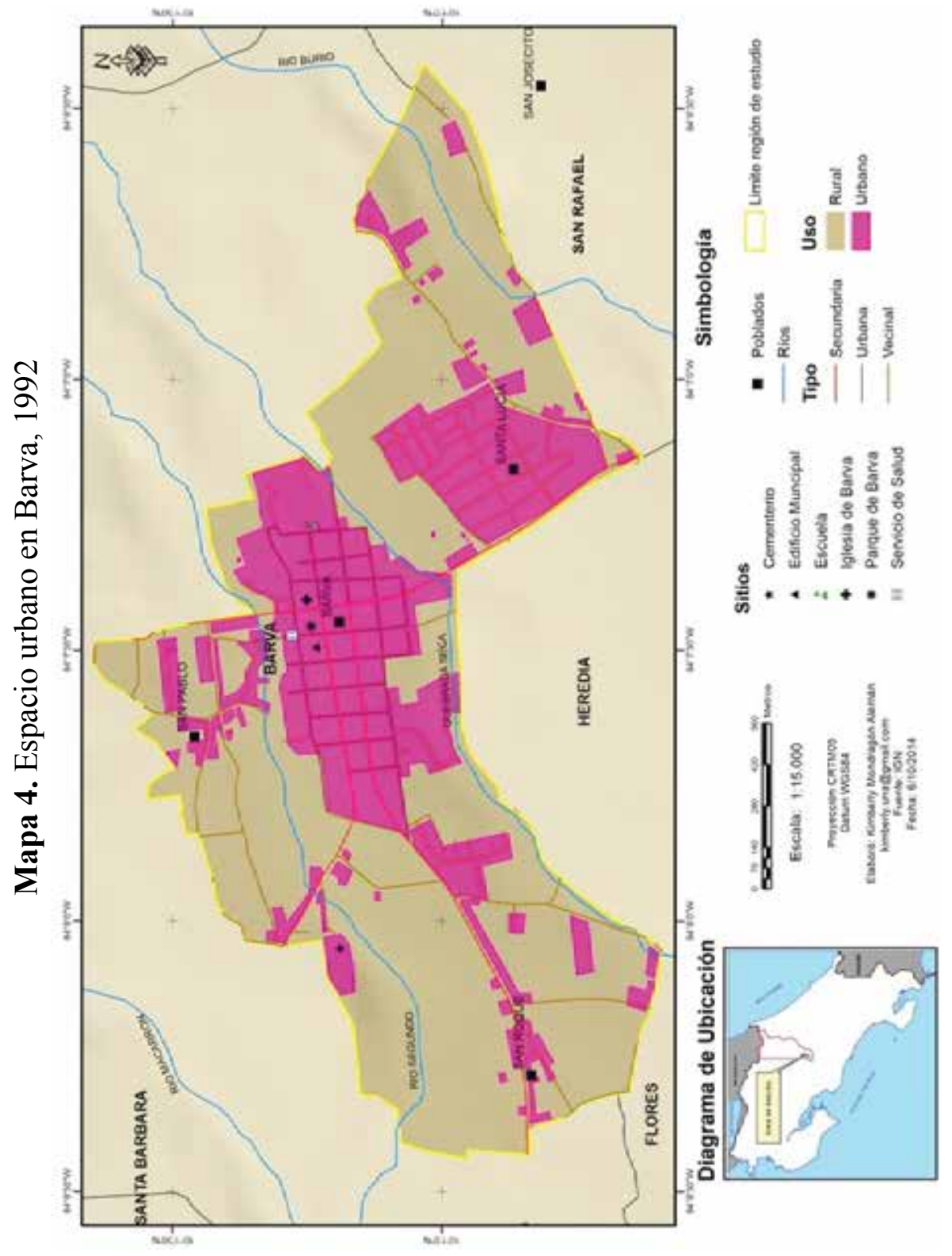

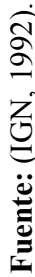


Tabla 3. Hallazgos censales y cartográficos del Cantón de Barva referentes al uso de suelo y población, 1990-2014

\begin{tabular}{|c|l|l|}
\hline Año & \multicolumn{1}{|c|}{ Fuente } & \multicolumn{1}{c|}{ Hallazgos } \\
\hline 1990 & $\begin{array}{l}\text { Estimación de } \\
\text { población }\end{array}$ & $\begin{array}{l}\text { Población cantonal: 24.694 habitantes, un 18,5\% vive en el } \\
\text { Distrito Central, un 14,6\% en Santa Lucía, un 9,9\% en San } \\
\text { Roque y un 16.59\% en San Pablo. }\end{array}$ \\
\hline 1992 & Mapa de 1992 & $\begin{array}{l}\text { Ríos Quebrada Seca y Segundo: elementos ordenadores del } \\
\text { crecimiento urbano (sentido este-oeste). } \\
\text { La expansión del distrito de Santa Lucía colindó a los } \\
\text { cantones Barva y Heredia provocando una conurbación } \\
\text { entre ambas localidades. } \\
\text { Aumento del área urbana en San Roque y San Pablo. }\end{array}$ \\
\hline 2000 & $\begin{array}{l}\text { Estimación de } \\
\text { población }\end{array}$ & $\begin{array}{l}\text { Población cantonal: 33.422 habitantes, un 15,1\% vive en el } \\
\text { Distrito Central, un 16,8\% en San Lucía, un 9,5\% en San } \\
\text { Roque y un 20.52\% en San Pablo. }\end{array}$ \\
\cline { 2 - 3 } & $\begin{array}{l}\text { Según criterio del INEC, los habitantes del Distrito Central } \\
\text { de Barva viven en una zona 100\% urbana, en Santa Lucía } \\
\text { lo hacen un 97,2\% de sus moradores y en San Roque un } \\
53,5 \%, \text { mientras que en San Pablo un 59,7\% viven en la } \\
\text { periferia urbana. }\end{array}$ \\
\hline 2010 & $\begin{array}{l}\text { Estimación de } \\
\text { población }\end{array}$ & $\begin{array}{l}\text { 40.123 habitantes registrados en el cantón, 12,1 \% vive en el } \\
\text { distrito central, un 18,9\% en Santa Lucía y un 8,5\% en San } \\
\text { Roque y un 24.88\% en San Pablo. }\end{array}$ \\
\hline 2014 & $\begin{array}{l}\text { Mapa de 2014 Roque, San Pablo y Santa Lucía muestran una cobertura } \\
\text { amplia de la zona urbana, en su mayoría es habitacional. } \\
\text { Centro urbano de Barva expandido por la proliferación } \\
\text { perimetral de edificaciones residenciales y comerciales, } \\
\text { resultado de la sustitución de un modelo de acumulación } \\
\text { de riqueza basado en la agricultura por uno de naturaleza } \\
\text { inmobiliario. }\end{array}$ \\
\hline
\end{tabular}

Fuentes: (Rosero, 2002; INEC, 2000, IGN, 1992, 2014).

En los mapas analizados del período, ya no se advierte el límite entre los cantones de Barva y Heredia. Santa Lucía se muestra integrada a ambos, generando un solo sector; San Roque, por su parte, presenta la ampliación de su zona urbana en el área colindante con el Distrito Central barveño y con el distrito de Mercedes Norte del cantón de Heredia, consolidando así la conurbación (Mapa 5). 
Marcela Otárola Guevara. Application of cartographic and censual tools in a historiographical study of the Central District of Barva, 1945-2014

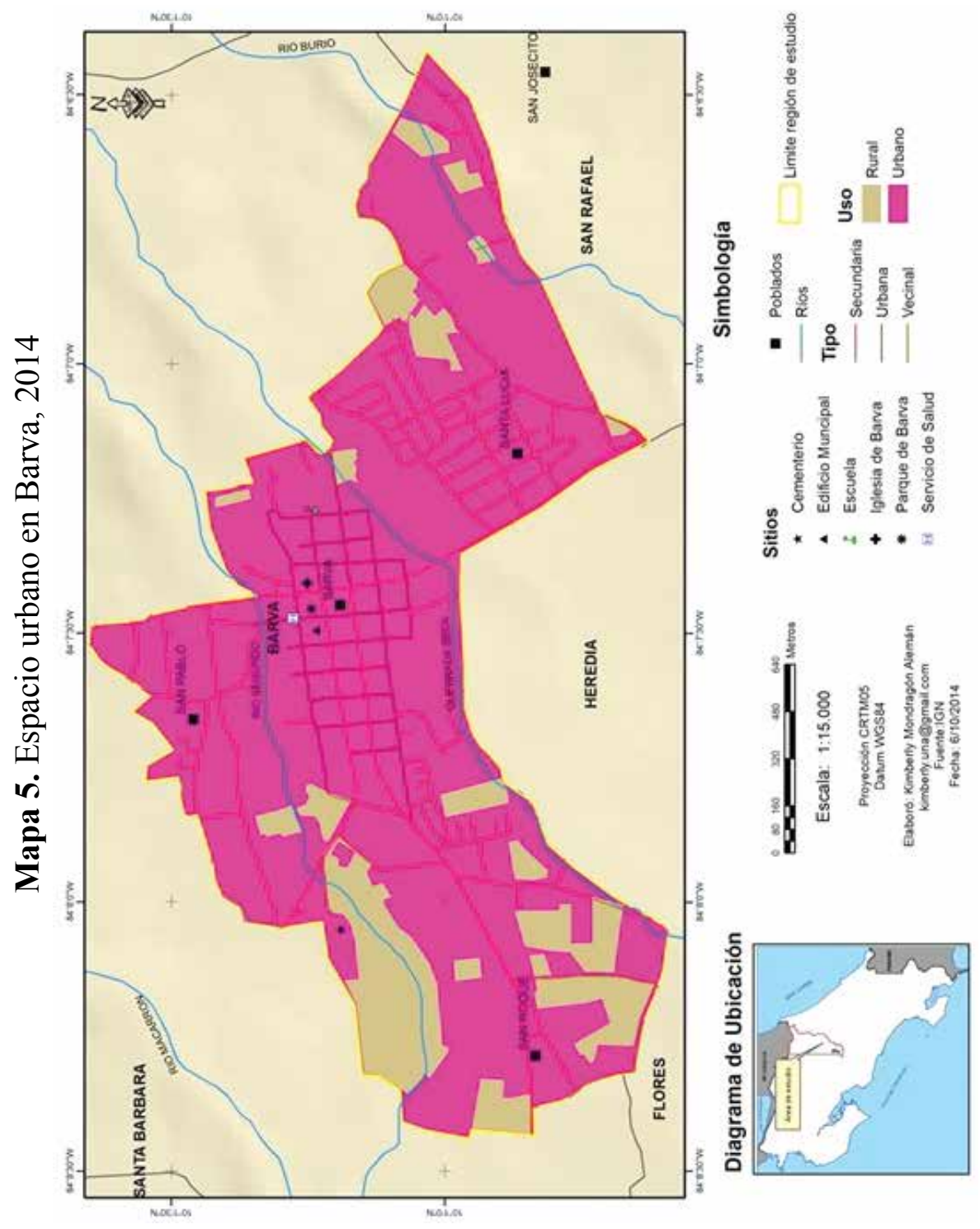

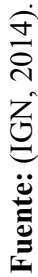


La conversión de esta zona de rural a urbana, revela un cambio en la forma social de la comunidad. Aparejado al cambio del uso del suelo, también se da un cambio en la población, además del aumento de su número. Ella se torna más heterogénea por el efecto de la migración de personas provenientes de otros cantones de la Gran Área Metropolitana (GAM), lo que se convierte en una condición que incide en la forma de interactuar de los habitantes.

\section{La transformación del centro urbano y la composición de la población}

Una red vial que integra al cantón con otros más populosos dentro y fuera de la provincia, la prestación de todos los servicios urbanos y una infraestructura institucional consolidada (DEPPAT, 2006), además de una oferta generosa de vivienda en urbanizaciones y condominios, llegan a constituir una parte importante de los atractivos que han propiciado la migración a este sector y, por ende, su transformación.

Testimonios y documentos aportados por informantes que colaboraron con la investigación exponen que, partir de 1980, empieza el desarrollo de proyectos habitacionales, este es motivado por la demanda de vivienda, y con su desarrollo provocaron las migraciones. Se construyen en torno al Distrito Central los proyectos Jardines de Santa Lucía, en Santa Lucía (área sureste), San Bartolomé y Juan Pablo II, en el Distrito Central (áreas sur y suroeste); así como La Armonía y El Ibis, en San Pablo (área norte). Para 1990, no sólo se densifican estas urbanizaciones, sino que surgen otras que amplían la superficie de vivienda: Santander y Puente de Piedra, en San Roque (área oeste); Santa Paula 1, en San Pablo (área noroeste); Don Abraham, en el centro (área sur) y Malinche Real, en Santa Lucía (área sureste).

Entre el 2000 y 2010, la mayor construcción de asentamientos inmobiliarios se produce en San Roque, Santa Lucía y San Pablo (sector oeste, sureste y norte, respectivamente). En el primero, se erigen: El Pórtico, Los Luises, Hacienda Nueva, La Plantación y Camino de Sol; en el segundo, se levantan los proyectos Doña Iris, Don Álvaro, Villa Esmeralda, Calle Vílchez; mientras que en el tercero: Monte Hiedra, Montecarlo y Santa Paula 2.

El volumen habitacional desplegado consolida la fusión de espacios entre Barva y Heredia, eleva el requerimiento de servicios urbanos, 
modificando la organización territorial. Para atender las demandas exigidas por esta situación, surgen nuevas obras: se funda, en el 2011, el Colegio Técnico Profesional de San Pedro de Barva; dos años después, se construye la nueva escuela Rafael Arguedas Gutiérrez en San Roque de Barva; en el 2014, se inicia la construcción de la Clínica de Barva, que contabiliza un área total de 5300 metros cuadrados, y se edifica el primer Centro de Cuido y Desarrollo Infantil en Santa Lucía. Igualmente, en el 2013, se reacondiciona la red vial al ampliarse a cuatro carriles el principal acceso al cantón: el puente sobre Quebrada Seca.

A modo de resumen, se presenta la incidencia de este comportamiento en la superficie urbana asociada a la configuración del sitio (Tabla 4):

Tabla 4. Cambios urbanos entre 1945 y 2014

\begin{tabular}{|c|c|c|}
\hline Fecha & Área urbana (m2) & Morfología urbana \\
\hline 1945 & 132799 & $\begin{array}{l}\text { - Centro urbano integrado por la plaza, la iglesia y la } \\
\text { municipalidad. } \\
\text { - Preponderancia de la red de caminos en la organiza- } \\
\text { ción del espacio urbano. }\end{array}$ \\
\hline 1960 & 395044 & $\begin{array}{l}\text { - Formación de cuatro barrios en el centro urbano distri- } \\
\text { tal: Chileperro, La Gruta, El Parque, El Triunfo. } \\
\text { - Reubicación de la escuela Pedro Murillo (700m al este } \\
\text { del edificio municipal) y la Unidad Sanitaria (costado } \\
\text { norte de la plaza). }\end{array}$ \\
\hline 1980 & 930962 & $\begin{array}{l}\text { - Crecimiento de poblados perimetrales como San- } \\
\text { ta Lucía, San Pablo y San Roque, que incrementó la } \\
\text { circulación de personas y mercancías provocando el } \\
\text { aumento de la flota vehicular y del tránsito en vías } \\
\text { principales y sus rutas alternas }\end{array}$ \\
\hline 1992 & 1325228 & $\begin{array}{l}\text { - Consolidación del centro urbano por desarrollo } \\
\text { comercial. } \\
\text { El desarrollo inmobiliario, básicamente residencial, } \\
\text { sustituyó la agricultura como forma productiva de ca- } \\
\text { pitalización de la tierra, en San Roque, Santa Lucía y } \\
\text { San Pablo estimulando la concentración de habitantes } \\
\text { en ellos. }\end{array}$ \\
\hline 2014 & 2674081 & $\begin{array}{l}\text { - } \text { Conurbación con Heredia. } \\
\text { - Reducción de espacios públicos recreativos. } \\
\text { - Definición de principales calles comerciales: acceso a } \\
\text { Barva y conexión con San Pedro. }\end{array}$ \\
\hline
\end{tabular}

Fuente: elaboración propia. 
Estas permutaciones en el centro urbano, que impactan significativamente su paisaje, son el resultado de sus cambios demográficos. El aumento de residentes ha sido importante, según información de los inventarios del Instituto Nacional de Estadística y Censos (INEC) en 1984 y 2011, pues se registra un incremento de la población de $115 \%$ en este período (Tabla 5). Este aumento no es la única variación que se puede apreciar en el cotejo. También, la composición del grupo de habitantes cambia y se evidencia en la cantidad de foráneos, ella asciende de un $40,4 \%$ a un $46,8 \%$ del total de la población. Vale mencionar que, aunque el conjunto inmigrante creció una vez y medio, la mayoría sigue siendo costarricense (96\%), lo cual ratifica la tendencia al poblamiento en esta región por gente de localidades circunvecinas.

Tabla 5. Comparación de la población del cantón de Barva entre 1984 y 2011

\begin{tabular}{|l|l|c|c|c|c|c|c|c|c|}
\hline \multirow{2}{*}{ Población total } & \multicolumn{2}{|c|}{$\begin{array}{c}\text { No migrantes } \\
\text { (total) }\end{array}$} & \multicolumn{2}{c|}{$\begin{array}{c}\text { Migrantes } \\
\text { (total) }\end{array}$} & \multicolumn{2}{c|}{$\begin{array}{c}\text { Migrantes } \\
\text { internos } \\
\text { (costarricenses) }\end{array}$} & \multicolumn{2}{|c|}{$\begin{array}{c}\text { Migrantes } \\
\text { externos } \\
\text { (extranjeros) }\end{array}$} \\
\cline { 3 - 10 } & $(\#)$ & $\mathbf{( \% )}$ & $\mathbf{( \# )}$ & $\mathbf{( \% )}$ & $\mathbf{( \# )}$ & $\mathbf{( \% )}$ & $(\#)$ & $(\%)$ \\
\hline $\begin{array}{l}\text { Barva (\#) } \\
(\mathbf{1 9 8 4 )}\end{array}$ & 18933 & 11286 & 59,6 & 7647 & 40,4 & 7332 & 95,9 & 315 & 4,1 \\
\hline $\begin{array}{l}\text { Barva (\#) } \\
(\mathbf{2 0 1 1})\end{array}$ & 40660 & 21616 & 53,2 & 19044 & 46,8 & 16856 & 88,5 & 2188 & 11,5 \\
\hline Aumento (\%) & 114,76 & 91,5 & & 149 & & 129,9 & & 594,6 & \\
\hline Aumento (\#) & 1,15 & 0,9 & & 1,5 & & 1,3 & & 5,95 & \\
\hline
\end{tabular}

Fuente: (INEC, 1984, 2011).

En este punto, cabe indagar sobre la procedencia de las personas que participan en esta movilización, y el Plan Regulador de Barva 2006, suministra datos que permiten esclarecerla. De acuerdo con esta fuente, la población en los distritos barveños denota un impacto asimétrico de la migración (Tabla 6); mientras que Barva, San Pablo, San Pedro y San José de la Montaña cuentan más de la mitad de sus moradores como originarios del distrito, acogiendo a un alto porcentaje de ciudadanos nacidos en territorio cantonal (56.38\% en promedio); Santa Lucía y San Roque revelan una exigua cantidad de habitantes locales - si se les compara con sus pares- $y$ un alto porcentaje de sujetos que proceden del resto de la provincia y 
de otros sectores del país, especialmente del denso espacio metropolitano concentrado en la ciudad capital (Carvajal, 2005).

Tabla 6. Composición de la población de los distritos del cantón de Barva, según su procedencia

\begin{tabular}{|l|c|c|c|c|c|}
\hline \multicolumn{1}{|c|}{ Distritos } & $\begin{array}{c}\text { Habitantes } \\
\text { oriundos } \\
\text { del mismo } \\
\text { barrio (\%) }\end{array}$ & $\begin{array}{c}\text { Migrantes } \\
\text { de otros } \\
\text { barrios } \\
\text { del mismo } \\
\text { distrito (\%) }\end{array}$ & $\begin{array}{c}\text { Migrantes } \\
\text { de otros } \\
\text { distritos } \\
\mathbf{( \% )}\end{array}$ & $\begin{array}{c}\text { Migrantes } \\
\text { de otros } \\
\text { cantones } \\
\mathbf{( \% )}\end{array}$ & $\begin{array}{c}\text { Migrantes } \\
\text { de otras } \\
\text { provincias } \\
\mathbf{( \% )}\end{array}$ \\
\hline Barva & 67,0 & 13,0 & 20 & 0 & 0 \\
\hline San Pedro & 55,0 & 12,2 & 10,8 & 14,4 & 7,7 \\
\hline San Pablo & 47,5 & 21,2 & 17,5 & 10,1 & 3,7 \\
\hline San Roque & 11,0 & 0 & 6,2 & 32,5 & 50,3 \\
\hline Santa Lucía & 27,0 & 0 & 0 & 73 & 0 \\
\hline San José de la Montaña & 56,0 & 0 & 22 & 22 & 0 \\
\hline
\end{tabular}

Fuente: (DEPPAT, 2006).

Los individuos que se han mudado a Barva procedentes de otros cantones, lo han realizado respondiendo a una oferta de vivienda y sus facilidades conexas. Datos censales del Instituto Nacional de Estadística y Censos (INEC), correspondientes a la primera década del siglo veintiuno, indican que hubo un aumento de un $45 \%$ en el número de viviendas contabilizadas: para el 2001, se registró 7.754 unidades, mientras que se reportaron 11.291 unidades para el 2011. Una revisión sobre proyectos residenciales en desarrollo, registrados por el gobierno local entre 19992009, revela que existieron 13 distribuidos en cinco distritos: Santa Lucía (cuatro), San Pedro (tres), San José de la Montaña (dos), San Roque (dos), San Pablo (uno) y Barva (uno).

Al triangular esta información con los mapas del cantón y sus zonas aledañas, correspondientes a 1980, 1997 y 2014, se aprecia que los asentamientos habitacionales se construyeron en antiguas fincas agrícolas (en su mayoría cafetales). Esta observación es coherente con lo afirmado en el apartado Principales actividades económicas y productivas del cantón del Plan de Desarrollo Humano Cantonal 2015-2020 del Cantón de Barva (Municipalidad de Barva, 2014), en el cual se indica que la vocación agrícola del cantón ha cambiado como consecuencia de una expansión 
urbanística, que ha traído consigo el desarrollo del sector terciario conjuntamente con el inmobiliario.

Servicios de salud, educación, finanzas, telecomunicaciones, un comercio bastante heterogéneo y una red vial diversificada (que conduce a varias localidades) son algunas ventajas que tiene el centro de Barva. Otras relacionadas con la evolución económica de cantones cercanos amplían estas prerrogativas. Una de ellas es la proximidad a nodos importantes de trabajo como recintos universitarios (Universidad Nacional, Universidad Central, Universidad Fidélitas, Universidad Latina), zonas francas (Parque Global, Ultrapark Lag, Zona Metropolitana, Baatca y los Arallanes) y áreas comerciales (circuito de negocios San Francisco de Heredia-San Joaquín, malles Real Cariari y Paseo Las Flores, junto con los oficentros que les rodean); los cuales constituyen polos de fuerte atracción y que movilizan a costarricenses de otras partes del país a vivir en esta región. Son estos emplazamientos laborales los que capturan un alto porcentaje del $43,8 \%$ de la población productiva ocupada del cantón (Tabla 7), y los que han contribuido al incremento de la densidad poblacional en sus distritos, especialmente, en Santa Lucía, San Roque y Barva centro, declarados jurisdicciones urbanas totales en el 2011 (Tabla 8).

Tabla 7. Ocupación de la población productiva en el cantón de Barva

\begin{tabular}{|l|l|l|}
\hline & \multicolumn{1}{|c|}{$\begin{array}{c}\text { Habitantes } \\
(\#)\end{array}$} & $\begin{array}{c}\text { Porcentaje de la } \\
\text { población (\%) }\end{array}$ \\
\hline Población total del cantón de Barva & $\mathbf{4 0 6 6 0}$ & $\mathbf{1 0 0}$ \\
\hline Población mayor de 15 años (en edad productiva) & 31575 & 77,7 \\
\hline Población fuerza de trabajo & 18243 & 44,9 \\
\hline Población ocupada & 17812 & 43,8 \\
\hline Población que realiza quehaceres del hogar & 5498 & 13,5 \\
\hline Población estudiantil & 3850 & 9,5 \\
\hline Otras situaciones & 2031 & 5 \\
\hline Población de pensionados & 1897 & 4,7 \\
\hline Población desocupada & 430 & 1,1 \\
\hline Población de rentistas & 56 & 0,1 \\
\hline
\end{tabular}

Fuente: (INEC, 2011). 
Tabla 8. Indicadores demográficos del cantón de Barva (2011)

\begin{tabular}{|l|c|c|c|}
\hline & Población (\#) & $\begin{array}{c}\text { Densidad de } \\
\text { población (\#) }\end{array}$ & $\begin{array}{c}\text { Porcentaje de población } \\
\text { urbana (\%) }\end{array}$ \\
\hline Total del cantón de Barva & $\mathbf{4 0 6 6 0}$ & $\mathbf{7 5 5 , 8}$ & $\mathbf{9 1}$ \\
\hline Barva & $\mathbf{4 9 9 7}$ & $\mathbf{7 9 3 1 , 7}$ & $\mathbf{1 0 0}$ \\
\hline San Pedro & 9932 & 1324,3 & 96,8 \\
\hline San Pablo & 8319 & 1221,6 & 80,9 \\
\hline San Roque & $\mathbf{4 6 2 2}$ & $\mathbf{3 9 8 4 , 5}$ & $\mathbf{1 0 0}$ \\
\hline Santa Lucía & $\mathbf{7 4 1 3}$ & $\mathbf{2 4 8 7 , 6}$ & $\mathbf{1 0 0}$ \\
\hline San José de la Montaña & 5377 & 154,9 & 67,6 \\
\hline
\end{tabular}

Fuente: (INEC, 2011).

El incremento de moradores en el cantón no se interrumpió: según proyectó Rosero Bixby (2002), para el 2015 fue de un 5,16\% con respecto al 2011. Santa Lucía continúa albergando nuevos vecinos y, a pesar de que Barva centro y San Roque se encuentran saturados residencialmente, el contingente de personas que arriba está ampliando la expansión de sitios circunvecinos como San Pablo y San Pedro (Tabla 9).

Tabla 9. Incremento de la población en Barva para el 2015

\begin{tabular}{|l|c|c|c|}
\hline & $\begin{array}{c}\text { Población } \\
\mathbf{2 0 1 1}(\#)\end{array}$ & $\begin{array}{c}\text { Proyección de } \\
\text { población 2015 (\#) }\end{array}$ & $\begin{array}{c}\text { Aumento de } \\
\text { población (\%) }\end{array}$ \\
\hline Total del cantón de Barva & $\mathbf{4 0 . 6 6 0}$ & $\mathbf{4 2 . 7 6 0}$ & $\mathbf{5 , 1 6}$ \\
\hline Barva & $\mathbf{4 . 9 9 7}$ & $\mathbf{4 . 7 7 3}$ & $\mathbf{- 4 , 4 8}$ \\
\hline San Pedro & 9.932 & 10.664 & 7,37 \\
\hline San Pablo & 8.319 & 11.297 & 35,80 \\
\hline San Roque & $\mathbf{4 . 6 2 2}$ & $\mathbf{3 . 4 9 6}$ & $\mathbf{- 2 4 , 3 6}$ \\
\hline Santa Lucía & $\mathbf{7 . 4 1 3}$ & $\mathbf{8 . 4 2 4}$ & $\mathbf{1 3 , 6 4}$ \\
\hline San José de la Montaña & 5.377 & 4.106 & $-23,64$ \\
\hline
\end{tabular}

Fuentes: (INEC 2011; Rosero, 2002).

El efecto del cambio demográfico se aprecia en el perfil laboral de los habitantes barveños. Una comparación entre las ocupaciones de la población, consignadas entre el 2000 y 2011, muestran un sector cada vez mayor de personas con un alto nivel educativo, el cual les permite emplearse 
en quehaceres científicos, técnicos y comerciales; mientras que las labores agropecuarias disminuyen drásticamente (Figura 1).

Figura 1. Comparación de las ocupaciones de los habitantes de Barva entre 2000 y 2011

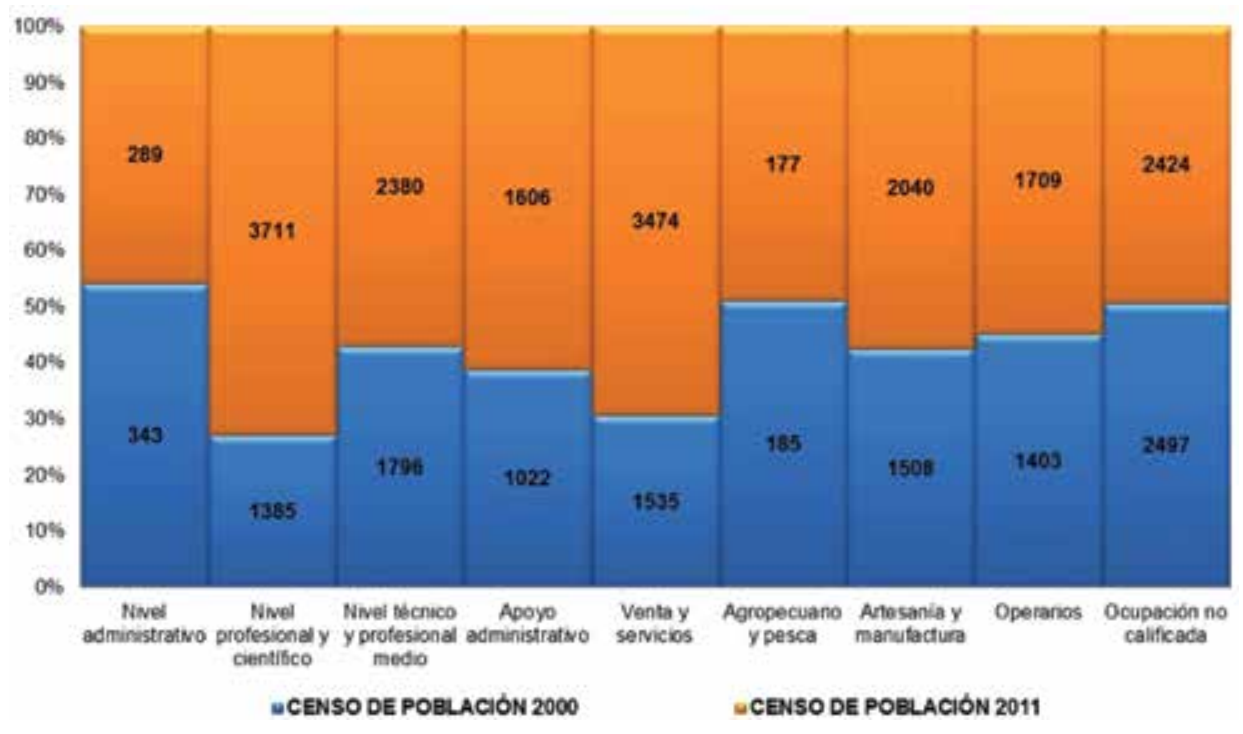

Fuente: (INEC, 2000, 2011).

\section{Conclusión}

El estudio de la composición morfológica del Distrito Central de Barva, realizando un seguimiento comparativo cartográfico y poblacional, reveló el origen de su expansión y transformación urbana en el siglo anterior y el proceso de formación de la comunidad de residentes en el siglo XXI.

Los mapas mostraron el crecimiento de su centro urbano en dos sentidos; uno que constituye un eje oeste-este, orientación establecida por dos ríos que corren hacia esos puntos y delimitan el asentamiento; y otro en dirección noroeste-sureste, siguiendo el trazo de la carretera 126. Así, esta expansión partió de un núcleo de población compacto, asentado sobre una trama urbana que se desarrollaría longitudinal, siguiendo un patrón fluvial, y transversalmente, continuando el recorrido de una ruta nacional. En ambos casos, las vías de acceso vehicular han tenido un papel importante, 
porque son los elementos articuladores de las diferentes actividades humanas que se realizan en la localidad.

Información de censos y documentos demográficos expusieron los cambios representativos en el uso de la tierra, como consecuencia del aumento de la densidad poblacional que provocó la disminución de las áreas de cultivo en el área de estudio. Este mismo patrón se repitió en distritos aledaños que empezaron a ensancharse hasta quedar unidos entre sí sin un límite visible que los distinga claramente, desplazando hacia la periferia los campos agrícolas. Éstos, para el año 2014 fueron relegados a las zonas montañosas que se ubican al norte y al este del Distrito Central y al oeste en San Pedro de Barva.

Por otra parte, los registros demográficos evidenciaron el cambio en el perfil de los residentes del distrito y mostraron una población heterogénea en cuanto a origen y ocupación. En el siglo pasado la mayoría de los pobladores nacieron en la localidad, situación que en las últimas dos décadas cambió, estableciendo porcentajes casi iguales entre residentes locales y foráneos. La mayoría de los inmigrantes trabajan en el sector de servicios y se han asentado en distritos perimetrales al central,respondiendo a una oferta diversa de proyectos habitacionales gregarios (residenciales y condominios) que han fomentado, a su vez, la ampliación de servicios de infraestructura, comercio, salud y educación; hechos que también abonaron al aumento de la zona urbana en detrimento de la rural.

Como se ha podido apreciar, la incorporación de la cartografía y de la demografía en investigaciones historiográficas urbanas favorece la comprensión de los fenómenos sociales que ocurren en las ciudades. En el caso concreto de estudio, con ellas se logró establecer una ubicación específica de la huella urbana en diferentes épocas, conocer su morfología mediante la medición de su superficie e identificación de uso y así, elucidar su procedencia; a la vez que se reconocieron y perfilaron a los agentes sociales promotores de las permutas urbanas. Con esta información es posible vislumbrar tendencias de extensión en la ciudad, posibles cambios de uso de suelo y cambios en la composición demográfica del cantón que incidirían en su estructura urbana; de allí, su aplicabilidad en proyectos relacionados con la toma de decisiones sobre su ordenamiento territorial. 


\section{Agradecimientos}

La autora agradece a la Dra. Carmen Araya Jiménez, al Dr. Carlos Hernández y a la M.Sc Lidia Orias, las contribuciones en la conducción del estudio que sustentó este artículo.

\section{Referencias}

Carvajal, G. (2005). La organización del espacio urbano de la ciudad de San José: temas y problemas a inicios del tercer milenio. San José, Costa Rica: Librería Alma Mater.

Desarrollos en Ecología, Paisajismo, Planificación, Arquitectura y Turismo (DEPPAT). (2006). Diagnóstico de Planificación del Plan Regulador de Barva de Heredia. San José, Costa Rica.

Desarrollos en Ecología, Paisajismo, Planificación, Arquitectura y Turismo (DEPPAT). (2008). Plan Regulador de Barva de Heredia. San José, Costa Rica.

Dirección General de Estadística y Censos. (1950). V Censo Nacional de Población. San José, Costa Rica.

Dirección General de Estadística y Censos. (1962). Mapa censal del Cuadrante de Barba. Escala 1:2000. San José.

Dirección General de Estadística y Censos. (1963). VI Censo Nacional de Población. San José, Costa Rica.

Dirección General de Estadística y Censos. (1972). Mapa censal del Distrito 1ero Barba. Escala 1:2000. San José.

Dirección General de Estadística y Censos. (1973). VII Censo Nacional de Población y III Censo Nacional de Vivienda. San José, Costa Rica.

Dirección General de Estadística y Censos. (1973). IV Censo Agropecuario. San José, Costa Rica.

Dirección General de Estadística y Censos. (1982). Mapa censal del Distrito 1ero Barba. Escala 1:2000. San José.

Dirección General de Estadística y Censos. (1984). VIII Censo Nacional de Población y IV Censo Nacional de Vivienda. San José, Costa Rica. Dirección General de Estadística y Censos. (1984). V Censo Agropecuario. San José, Costa Rica.

Instituto Nacional de Estadísticas y Censos. (2000). IX Censo Nacional de Población y V Censo Nacional de Vivienda. San José, Costa Rica. 
Instituto Nacional de Estadísticas y Censos. (2011). X Censo Nacional de Población y VI Censo Nacional de Vivienda. San José, Costa Rica.

Instituto Geográfico Nacional (IGN). Fotografías aéreas del Distrito Central de Barva, años 1945, 1960, 1980, 1985, 1992, 1997 y 2014. Archivo Institucional, San José, Costa Rica. Consultado en el 2014. Municipalidad de Barva. (2014). Plan de Desarrollo Humano Local de Barva 2015-2020. Recuperado de http://munibarva.go.cr/documentos/Planes\%20Anuales\%20Operativos/PLAN_DE_DESARROLLO_HUMANO_LOCAL.pdf

Rodríguez, P. (1997). Historia del Cantón de Barva. Estudio de lo local como identidad. San José, Costa Rica: Editorial Mirambell.

Rosero, L. (2002). Estimaciones y proyecciones de población por distrito y otras áreas geográficas. Costa Rica 1970-2015. Recuperado de http://ccp.ucr.ac.cr/bvp/pdf/proye/distrital.pdf

Solera, G. (1964). El Cantón de Barba. Apuntes Históricos de Fundación y Progreso 1562-1964. San José, Costa Rica: Imprenta Nacional. 